\title{
CONTROI IN ECONOMY BASED ON NON-PRICE INFORMATION
}

\author{
I.LIGETI - J.SIVÁR \\ Institute of Economic Planning \\ 1370. Budapest, Pf.610. \\ HUNGARY
}

In his Anti-Equilibrium J.Kornai analyzed the various components of the functioning of economic systems/Kornai, 1971/. Apart from the two extreme control mechanisms - control by prices and control by instructions - he discusses also the so called autonomous control mechanism. One of the simplest cases of autonomous control is the control based on stock signals. In an article J.Kornai and B.Martos discussed the case of control based on stock signals in a simple model of a Leontief-type economy /Kornai-Martos, 1973/.

The present paper aimes to throw light on some new components of autonomous functioning relying on a simple model. Analogy between economic processes and physical phenomena plays an important part here.

The first part of the paper describes the model. Then we proceed to analyze the conditions of the functioning of the economic system. This is followed by the generalization of the model after removing some of the simplifying assumptions. $1 /$

Notation $s$

a) Variables /all variables are functions of time/

$i j$ - indexes of economic units $(i, j=1,2, \ldots n)$

$x$ - vector of the production,

$x$ - diagonal matrix of vector $x$, where $x_{i i}=x_{i}$

$u$ - vector of the producer's stock

$\mathrm{V}$ - matrix of the user's stock $V_{i j}$ - stock at the j-th sector of the product of the i-th sector

$\mathrm{Y}$ - matrix of the user's purchase

1/ We are indebted to István Dancs for his valuable and efficient guidance in our research of autonomous control. The same is due to Csaba Csernatony for his assistance in preparing the final version of the present paper. 


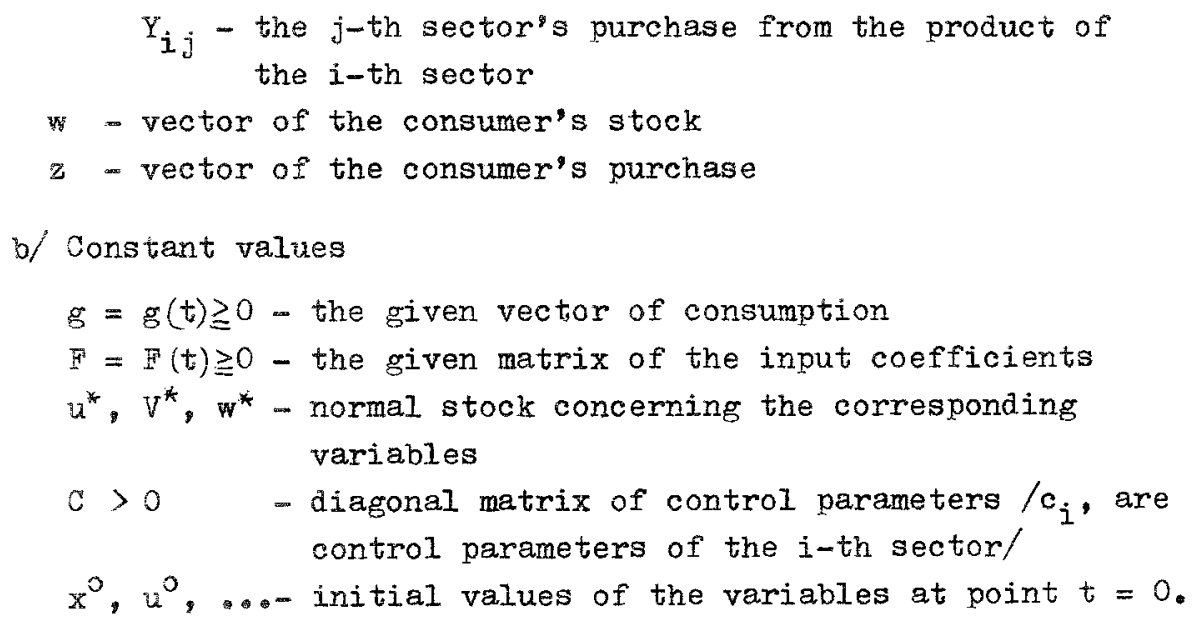

Small letters indicate vectors of $n$ components, capital letters indicate matrices. The components of the vectors and elements of the matrices are marked with superscript. The $e_{j}$ denotes the $j$-th unit vector, by $e$ we denote the summarizing vector. The unit matrix is denoted by $E$.

\section{The Model of a Ieontief-type Economy}

The economy is divided into two spheres: the sphere of $r$ a a $I$ processes and the sphere of $c \circ n t x \circ 1$. Naterial processes/production, transport, consumption, etc./ take place in the real sphere. In the sphere of control the information necessary for the control is collected and it is also here that the decisions are made.

According to Komai's definition the a ut o n o mo us control mechan $\mathrm{c}$ s m satisfies the following conditions:

- the aconomy has only one level/independent economic units exist only and there is no central co-ordinating unit/,

- decision-making is completely decentralized,

- decision-making and the control of the functioning of economic units take place through non-price-type parameters/e.g. signalling based on production, stocks/.

A simple case of autonomous control is control based on stock signals. The individual economic units make their own decisions by comparing their own stock level with some pre-fixed normative stock level. Thus, if the stocks exceed the given normative level, the produ- 
cer diminishes the output and vica versa. It means that the economic unit has such primary activities which are autonomously controlled by the system according to a primary adjustment rule. In essense this type of control is similar to the functioning of the sympathetic nervous system /Komai, 1971/.

The as $\mathbf{s}$ mptions of the model

1. The variables of the model are continuously differentiable with regard to time $t \geqq 0$. The values of the variables for $t=0$ are given as constants: $x^{\circ}$ etc.

2. All the variables are practically observable magnitudes and of deterministic character.

3. One single consumer is considered.

4. The real sphere of the economy is of closed Leontief-type.

5. The input-coefficient matrix $F(t)$ is nonnegative, continuously differentiable and its spectral radius is less than 1 for $t \geqq 0$.

6. Starting stocks $u^{0}, v^{0}, w^{0}$ are positive magnitudes.

On the basis of assumptions $1-6$ and according to the two spheres the model takes the following from: $1 /$

B a 1 anc e equations:

$$
\begin{array}{lr}
\dot{u}=x-Y e-z \\
\dot{v}= & Y-F X \\
\dot{w}= & z-g
\end{array}
$$

/I/

$$
\begin{aligned}
& \text { Rules of behaviour } \\
& \dot{\mathrm{X}}=\dot{\mathrm{Y}} \mathrm{e}+\dot{\mathrm{z}}+\mathrm{C}^{2}\left(\mathrm{u}^{*}-u\right) \\
& \dot{\mathrm{Y}}=\dot{\mathrm{H}}+\dot{\mathrm{H} X}+\mathrm{C}^{2}\left(\mathrm{~V}^{*}-\mathrm{V}\right) \\
& \dot{\mathrm{z}}=\dot{\mathrm{g}}+\mathrm{C}^{2}\left(\mathrm{w}^{*}-\mathrm{w}\right)
\end{aligned}
$$

I/ A discrete version of the model has also been elaborated/Dancs I.Hunyadi L. 1972.,1973/. However, here we rely on the continuous form of the model only. 
Taking into consideration that $\ddot{u}=\dot{x}-\dot{Y} e-\dot{z}$ and inserting this into the equation $\dot{x}=\dot{Y} e+\dot{z}+c^{2}\left(u^{*}-u\right)$ we get:

$$
\ddot{u}=c^{2}\left(u^{*}-u\right)
$$

By using similar substitutions the original model can be transformed into the following from:

Ba 1 ance equations

$$
\begin{aligned}
& \dot{v}=x-Y e-z \\
& \dot{V}=Y-F X \\
& \dot{w}=z-g
\end{aligned}
$$

/II/

$$
\begin{aligned}
& R u l e s \circ z \text { be } n \text { aviourl/ } \\
& \ddot{u}=c^{2}\left(u^{*}-u\right) \\
& \ddot{V}=c^{2}\left(V^{*}-V\right) \\
& \dot{w}=c^{2}\left(w^{*}-w\right)
\end{aligned}
$$

This new system of equations is called the transformation of the original model. It is easy to prove, that this system is equivalent to the original one given in the article of Kornai-Martos.

2. The solution of the model

The solution of this model - which is naturally the same as that of the original model - takes the following form:

$$
\begin{aligned}
& u=u^{*}+\cos C t\left(u^{0}-u^{*}\right)+C^{-1} \sin C t\left(x^{0}-Y e^{0}-z^{0}\right) \\
& V=V^{*}+\cos C t\left(V^{\circ}-V^{*}\right)+C^{-1} \sin C t\left(Y^{\circ}-x^{\circ} X^{\circ}\right) \\
& w=w^{*}+\cos C t\left(w^{\circ}-w^{*}\right)+C^{-1} \sin C t\left(z^{\circ}-g^{0}\right) \\
& Y=F X-C \sin C t\left(V^{\circ}-V^{*}\right)+\cos C t\left(Y^{\circ}-F^{\circ} X^{\circ}\right) \\
& z=g-C \sin C t\left(w^{0}-w^{*}\right)+\cos C t\left(z^{0}-g^{\circ}\right) \\
& x=\left(E-H^{-1}\left[g-C \sin C t\left(u^{\circ}-u^{*}+V^{\circ} e-V^{*} e+w^{0}-w^{*}\right)+\right.\right. \\
& \left.+\cos C t\left(x^{0}-F^{0} X^{0} e-g^{\circ}\right)\right]
\end{aligned}
$$

IT The "rules of behaviour" describe the behaviour of the economic units. In the control-theory the rules of this type are often called response functions. 
For the analysis of the properties of this solution let us regard the $j$-th co-ordinate of $u$ :

$$
u_{j}=u_{j}^{*}+\cos c_{j} t\left(u_{j}^{\circ}-u_{j}^{*}\right)+\frac{1}{c_{j}} \sin t\left(x_{j}^{0}-\sum_{l} Y_{j I}^{0}-z_{j}^{0}\right)
$$

Through transformation the following formula is obtained

$$
u_{j}=u_{j}^{*}+I_{j}^{u} \sin \left(c_{j} t+\varphi^{o}\right)
$$

where

$$
\begin{aligned}
& \varphi^{0}=\operatorname{arc} \sin \frac{u_{j}^{0}-u_{j}^{*}}{I_{j}^{u}} \\
& I_{j}^{u}=\frac{I}{c_{j}} \sqrt{c_{j}^{2}\left(u_{j}^{0}-u_{j}^{*}\right)^{2}+\left(x_{j}^{0}-\sum_{l} Y_{j I}^{0}-z_{j}^{0}\right)^{2}}
\end{aligned}
$$

It can easily be seen that the mathematical forms of the behavioural rules in the transformed version of the model are similar to differential equations describing harmonic oscillation where is no damping. In view of the above form of the solution we can make statements on the stock level of economic units with the behavioural equations given in the model, which will be similar to those of characteristics of harmonic oscillation.

The important caracteristics of this autonomous control are: ${ }^{1 /}$

if The value of production stock is a periodic function of time for any positive value of the control parameters. The centre of oscillation is the pre-fixed norm $u^{*}$.

ii/ The amplitude of the periodical oscillation is constant. Its magnitude depends on the actual value of the control parameters and on the given initial value of the variables.

iii/ The period of oscillation is constant, too.

The solution of the model gives rise to two issues:

I/ In what follows we shall examine only the production stock variables, since the other variables can easily be explained in a similar manner. For detailed analysis see the papers referred to. 
1. With the given behavioural rules can the functioning of the system be ensured in accordance with a definition to be given later.

2. What properties will the solution of the model have if the behavioural rules are changed.

The article of Kornai - Martos was followed by a comprehensive work to study autonomous control. These works were connected primarily with issue 2. Virág, 1971./. The fact that the behavioural equations of the transformed model are identical with those of harmonic oscillation provides the possibility for defining behavioural equations ensuring the dampening of oscillation. One solution is that a dampening factor is built in the equation which corresponds to the frictional force in the case of harmonic oscillation. Behavioural equation obtained in this manner can be given good economic interpretations. The solutions of the new system produce results similar to damped oscillations. /Dancs Hunyadi - Sivák, 1973. Si vák, 1974/.

These investigations have aimed primarily at the stability properties of the solution and less attention has been devoted to the workabilitity of the model.

\section{The workability of the system}

The concept of workability is interpreted in respect of the economic contents of the model.

Definition: system I/or II/ is regarded workable if the following conditions hold for its solutions:

$\begin{array}{ll}(3.1 .) & x>0, \\ (3.2 .) & u>0, \\ (3.3 .) & v>0, \\ (3.4 .) & w>0 .\end{array}$

1. The ore m:

In a systen satisfying conditions $1 .-6$. the model I/and thus also the model II/ has a solution which is workable in the sense of the above definition $i . e$. the values of $u^{*}, V^{*}$ and $w^{*}$ as well as $C$, have such a system in which $3.1-3.4$ conditions are satisfied. 
P $r \circ \circ f$ : To satisfy condition ( 3.2 ) the following relationship should be ensured

$$
\text { (3.5.) } \quad u^{*}>I^{u}
$$

Writing it for one co-ordinate

$$
u_{j}^{*}>I_{j}^{u}
$$

i.e. $\quad u_{j}^{*}>\frac{1}{c_{j}} \sqrt{c_{j}^{2}\left(u_{j}^{0}-u_{j}^{*}\right)^{2}+\left(x^{0}-\sum_{I} Y_{j I}^{0}-z_{j}^{0}\right)^{2}}$

Utilizing that $\dot{u}(0)=x^{0}-\sum Y_{j l}^{0}-z_{j}^{0}$,

after transformation the following formula is obtained:

$$
c_{j} u_{j}^{*}>\sqrt{c_{j}^{2}\left(u_{j}^{0}-u_{j}^{*}\right)^{2}+\dot{u}_{j}(0)^{2}}
$$

Similarly, to satisfy (3.3.) or (3.4.) it is necessary that

or

$$
\begin{aligned}
& c_{j} v_{j I}^{*}>\sqrt{c_{j}^{2}\left(v_{j I}^{0}-v_{j I}^{*}\right)^{2}+\dot{v}_{j I}(0)^{2}} \\
& c_{j} w_{j}^{*}>\sqrt{c_{j}^{2}\left(w_{j}^{0}-w_{j}^{*}\right)^{2}+\dot{w}_{j}(0)^{2}}
\end{aligned}
$$

Let us take that

$$
\text { (3.6.) } \quad \begin{aligned}
u_{j}^{*} & =u_{j}^{0} \\
v_{j l}^{*} & =v_{j l}^{o} \\
w_{j}^{*} & =w_{j,}^{o},
\end{aligned}
$$

and the values of the $c_{j}$ parameters according to the following formula

$$
\text { (3.7.) } c_{j}>\max \left\{\frac{\dot{u}_{j}(0)}{u_{j}^{0}} ; \max _{1} \frac{\dot{v}_{j l}(0)}{v_{j 1}^{0}} ; \frac{\dot{w}_{j}(0)}{w_{j}^{0}}\right\}
$$

With such values the condition $u_{j}^{*}>I_{j}^{u}$ /and with this also $V_{j l}^{*}>I_{j}^{V}, w_{j}^{*}>I_{j}^{W} /$ is satisfied which ensures that conditions (3.2.) (3.4.) are also met. 
With a similar line of argument we can guarantee that condition (3.1.) is aloo met.l

Let us come back to our condition $u_{j}^{*}>I_{j}^{u}$. After rearrangement the following formula is obtained:

$$
\text { (3.8.) } \quad \frac{1}{2} c_{j}^{2}\left(u_{j}^{0}-u_{j}^{*}\right)^{2}+\frac{1}{2} \dot{u}(0)^{2}<\frac{1}{2} c_{j}^{2} u_{j}^{* 2}
$$

If we make use of the e $n$ e $r g$ g $\circ$ o $c$ e $t$ of harmonic oscillation apart from the analogy found in the solution another one can be discovered.

We know, that the sum of the kinetic $\left(E_{k i n}\right)$ and potential energy (E $E_{\text {pot }}$ ) constitutes the energy (E) of the oscillating body.

Utilizing the fact that the equation of movement $1 /$ of our system is as follows:

$$
\ddot{u}_{j}=c_{j}^{2} u_{j}^{*}-c_{j}^{2} u_{j}
$$

the "energy of production stocks" will be

$$
\text { (3.9.) } \quad E^{u}=E_{k i n}^{u}+E_{p o t}^{u}=\frac{1}{2} \dot{u}^{2}+\frac{1}{2} c^{2}\left(u-u^{*}\right)^{2}
$$

Making use of this latter formula the analogy is self evident. The formula (3.8.) obtained from the condition $u_{j}^{*}>I_{j}^{u}$ arter rearrangement is nothing else than

$$
\text { (3.30.) } \quad \mathrm{g}^{\mathrm{u}}(0)<\mathrm{E}_{\mathrm{pot}}^{\mathrm{u}^{*}}
$$

where $\mathrm{E}^{\mathrm{u}}(0)$ is the energy at the starting-point and $\mathrm{E}_{\text {pot }}^{\mathrm{u}^{*}}$ the potential energy associated with the stock norm. Making use of this analogy the following consequences are encountered.

\section{Consequences:}

The necessary and sufficient condition of system I/and II/ being workable according to conditions (3.1.)-(3.4.) is that the following If the equation is given here for $u$ only. In a similar manner it can be given for the other variables, too. 
relationships are met

$$
\begin{array}{ll}
(3.2 .) & \mathrm{E}^{\mathrm{u}}(0)<\mathrm{E}_{\text {pot }}^{\mathrm{u}^{*}} \\
\text { (3.3.) } & \mathrm{E}^{\mathrm{V}}(0)<\mathrm{E}_{\text {pot }}^{*} \\
\text { (3.4.) } & \mathrm{E}^{w}(0)<\mathrm{E}_{\text {pot }}^{w^{*}}
\end{array}
$$

In a special case e.g. when $u_{j}^{o}=u_{j}^{*}$ the condition (3.2.) takes the following form $E_{k i n}^{u}(0)<E_{\text {pot }}^{u}(\ell)$.

4. A possible generalization of the model

After having examined the workability of the system let us focus our attention to the second issue. Supposing some modification in the behavioural miles a generalization of the model can be discussed.

In the above investigations the desired or pre-fixed stock level was considered constant. However, it seems reasonable to assume that it also changes over time. The desired stock level of the consumer or producer units may be different in the different economic situations. The stock level held constant in the model so far will be treated differently.

Two possible cases will be examined. The first one is a rather general case where the function describing the desired stock level is not specified. The other case is a special one.

1. Iet us take first the case where the actual stock level has an influence on the desired stock level. We will try to illustrate it with an example.

Let us take a consumer who has a certain amount of stock. His opinion of the prospectives varies depending on whether he has a small or large stock. Let us assume that the consumer in question has a stock of food sufficient for a week. In view of this he is optimistic concerning the situation at the market and he feels a stock for five days would be sufficient. On the other hand if his stock of food is at the zero level he is more anxious and less optimistic. Perhaps at first he tries to ensure a stock for one or two days but given the possibility of similar emergency situations, he may want to purchase stock for 
eight-ten days. Naturally it is difficult to put this relationship in a formula, however, we may assume that it does not distrort very much the actual stock level.

It is uncertain even in this case, however, how this effect appears over time. This may be defined so that if $f$ is a function expressing the desired stock levels how far the resultant stock $\left(u_{1}(t), u_{2}(t)\right.$ ), may be from one another? $1 /$

Let us consider the following a $s \mathrm{~s} u \mathrm{~m} i \mathrm{i}$. for the function $f:$

$$
\text { (*) }\left\|f\left[u_{1}(t)\right]-f\left[u_{2}(t)\right]\right\| \leqslant \gamma\left\|u_{1}(t)-u_{2}(t)\right\|
$$

where $t>0$ is a scaler.

In accordance with the above conditions the assumption expresses that small stock level differences /right hand side/ are accompanied with small differences/left hand side/ in the desired stock level.

Let us define the behavioural equation formulated in the above sense:

$$
\ddot{u}(t)=c^{2}[f(u(t))-u(t)]
$$

The task cannot be solved in an explicit form. In the following we try to give an upper estimate for the possible divergence.

The solutions of the model can implicitly be expressed in the following form:

$$
\begin{array}{ll}
\text { (4.1.) } & u_{1}(t)=e^{Q t} u_{1}(0)+e^{Q t} \int_{0}^{t} e^{-Q \tau} f\left(u_{1}(\tau)\right) d \tau \\
(4.2 .) & u_{2}(t)=e^{Q t} u_{2}(0)+e^{Q t} \int_{0}^{t} e^{-Q \tau} f\left(u_{2}(\tau)\right) d \tau
\end{array}
$$

1/ Further on we are going to analyze only one variable of the model. However, due to the special structure of the model the analysis does not loose generality. 
where

$$
e^{Q t}=\left(\begin{array}{cc}
\cos C t & C^{-1} \sin C t \\
-C \sin C t & \cos C t
\end{array}\right), Q=\left(\begin{array}{ll}
0 & E \\
-c^{2} & 0
\end{array}\right)
$$

Differences of the solutions can be measured with the norm of deviation. The behaviour of the deviation over time can be estimated with the help of the norm as a scalar.

Let us make use of the following lemmas:

1. I e m m a : Let $\varphi, \psi, \chi$ be real-valued continuous /or piecewiese continuous/ functions on a real $t$ interval $I: a \leq t \leq b$. Let $X(t)>0$ on $I$, and suppose for $t \in I$ that $\varphi(t) \leqq \psi(t)+\int_{0}^{t} \chi(s) \varphi(s) d s$ then $\varphi(t)$ can be estimated in the form:

$$
\begin{aligned}
\varphi(t) \leqq \psi(t)+\int_{a}^{t} \chi(s) \psi(s) \exp \left[\int_{s}^{t} X(u) d u\right] d s \\
\text { /Coddington- } \\
\text { Levinson, 1955/ }
\end{aligned}
$$

2. I e $\mathrm{m} \mathrm{ma}$ : Let $\|\cdot\|$ denote the matrix norm induced by the euclidean norm/known as spectral norm/ and, if $A \in C_{n \times n}$, let $\lambda_{A}$ be the spectral radius of $A^{*} A$, then $\|A\|=\lambda_{A}^{1 / 2}$ /Lancaster, 1969/.

3. I e $\mathrm{m} \mathrm{a}$ : A constant upper bound can be found for the operator norm of the $\mathrm{e}^{2 \mathrm{t}}$. /Dancs - Ligeti,1973/.

2. Theorem: If $f$ satisfies the (*) assumption and (4.1.), (4.2.) hold for $v_{1}(t)$ and $u_{2}(t)$, the estimation for the solution growths exponentially, if $t \rightarrow \infty$.

Proof:

Let us take the difference between (4.1.) and (4.2.)

$$
\begin{aligned}
u_{1}(t)-u_{2}(t)= & e^{\partial t}\left[u_{1}(0)-u_{2}(0)\right]+e^{Q t} \int_{0}^{t} e^{Q \tau}\left[f\left(u_{1}(\tau)\right)-\right. \\
& \left.-f\left(u_{2}(\tau)\right)\right] d \tau
\end{aligned}
$$


Let us take the norm of the expression and use the (*)assumption

$(* *)\left\|u_{1}(t)-u_{2}(t)\right\| \leq\left\|e^{Q t}\right\| \quad\left\|u_{1}(0)-u_{2}(0)\right\|+\left\|e^{Q t}\right\| \int_{0}^{t}\left\|e^{-2 \tau}\right\||\gamma| \| u_{1}(\tau)-$

$$
-u_{2}(\tau) \| d \tau
$$

Let us use the following notations:

$$
\begin{aligned}
& \varphi(t)=\left\|u_{1}(t)-u_{2}(t)\right\| \\
& \psi(t)=\left\|e^{Q t}\right\|\left\|u_{1}(0)-u_{2}(0)\right\| \\
& \chi(t)=\left\|e^{Q t}\right\| e^{-Q}|\gamma|
\end{aligned}
$$

In accordancne with the 3. Iemma the majorant for $e^{2 t}$ is a constant

$$
\begin{aligned}
& \psi(t)=K_{1}\left\|u_{1}(0)-u_{2}(0)\right\| \\
& \chi(t)=K_{2}|\gamma|
\end{aligned}
$$

where $\mathrm{K}_{1}, \mathrm{~K}_{2}$ are properly chosen constants.

Using the above notations we may apply the lemma 1. for $(* *)$ :

$$
\varphi(t) \leqq K_{1}\left\|u_{1}(0)-u_{2}(0)\right\|+K_{1}\left\|u_{1}(0)-u_{2}(0)\right\| \cdot K_{2}|\gamma| \int_{0}^{t} e^{\int_{\tau}^{t} K_{2}|\gamma| d u} d \tau
$$

After integration we can obtain the following expression:

$$
\varphi(t) \leqq K_{1}\left\|u_{1}(0)-u_{2}(0)\right\| e^{K_{2} \hbar t} \|
$$

2. Let us examine such a case where we assume that the function $f$ is knowm. Let us assume that there is an excess supply of a certain commodity at the market. The producer and consumer unit see their supply ensured, therefore they aim at a lower stock level. However, sooner or later these reserves are depleted and in some cases shortages appear. As a consequence the behaviour of the consumer and of the producer units changes, they try to achieve higher stock levels. Let us assume that this behaviour can be described with following function:

$$
f(t)=u^{*}+\bar{u} \cos A t
$$


where: $\bar{u}$ and $A$ are the parameters of changing behaviour, $A$ is diagonal. The function of behaviour can be formulated in the following form:

$$
\ddot{u}=C^{2}\left(u^{*}-\bar{u} \cos A t-u(t)\right)
$$

Let us see how this system behaves in this case. It is known that the solution of the original system can be given in the following form:

$$
u_{j}=u_{j}^{*}+K_{j} \sin \left(c_{j} t+\varphi_{j}^{0}\right)
$$

For the complete solution we have to know the correction factor, the periodic part which is determined by the following integral

$$
\int_{0}^{t} e^{Q(t-\tau)}\left(\begin{array}{l}
0 \\
\bar{u} \cos A \tau
\end{array}\right) d \tau
$$

After the integration is performed we are left with

$$
\begin{gathered}
\int_{0}^{t} e^{Q(t-\tau)}\left(\bar{u}_{\bar{u}}^{0} \cos A \tau\right) d \tau=(\cos A t-\cos C t)\left(C^{2}-A^{2}\right)^{-I} \bar{u}= \\
=\frac{t^{2}}{2} \bar{u} \frac{\sin \frac{A+C}{2} t \sin \frac{A-C}{2} t}{\frac{A+C}{2} \cdot \frac{A-C}{2} t}
\end{gathered}
$$

We can examine by components those cases where the $C$ and $A$ parameters are close to each other.

Since

$$
\lim _{a_{j} \rightarrow c_{j}}\left(\cos a_{j} t-\cos c_{j} t\right)\left(c_{j}^{2}-a_{j}^{2}-1 \bar{u}_{j}=-\frac{\bar{u}_{j}}{2 c_{j}} t \sin c_{j} t\right.
$$

is a function with increasing pendicity over t. The complete solution of the system oscillates with increasing amplitude.

Analyzing the interpretation of the $\mathrm{C}$ and $\mathrm{A}$ parameters it can be pointed out that if the two behavioural parameters are close to each other similarly to the physics, $r$ e $s$ o $n$ a $c e$ as such occurs also in the economy. The value of the $A$ parameter if inadequately chosen 
/measures taken at wrong time or unexpected reaction of the consumers and producers/may bring about resonance also in the economy.

\section{References}

CODDINGTON, A. - IEVINSON, N.: Theory of Ordinary Differential Equations, Mc Graw-Hill Book Co. 1955.

DANCS I. - LIGETI I.: Gazdasági rendszer słabilitésának vizsgálata. /Stability analysis of a dynamic economic system,/ Institute of Economic Planning, Hungary, Working Paper,1973.

DANCS,I. - HUWYADI, I. - SIVÁK,J.: Készletjelzésen alapuló szabályozés egy Ieontief tipusu gazdaságban /Control based on stock signals in a Ieontief-type economy/, Szigma, Vol.VI. No.3. /1973/. pp. 185-207.

IANCASTER, P.: Theory of matrices, Academic Press, New-York-Iondon,1969. KORNAI,J. - MARTOS, B.: Autonomous functioning of an economic system. Econometrica, Vol. 41. No.3. /1973/ pp. 509-529.

KORNAI,J.: Anti-equilibrium. North-Holland Publishing Co.Amsterdam,1971.

SIVÁK, J.: Control Based on Stock Signals, Paper presented on the Winter Symposium of Econometric Society, Budapest, January 1974.

VIRÁG, I. : Gazdasági rendszerek vegetativ miködése sztochasztikus kuilső fogyasztással / Autonomous functioning of an economic system with extermal stochastic consumption/ Szigma, Vol.VI. No.4. /1971/ pp. 261-268. 